\title{
Diversidade metabólica e atividade microbiana no solo em sistema de integração lavoura-pecuária sob intensidades de pastejo
}

\author{
Luis Fernando Chávez ${ }^{(1)}$, Luisa Fernanda Escobar ${ }^{(1)}$, Ibanor Anghinoni(1), \\ Paulo César de Faccio Carvalho(2) e Egon José Meurer ${ }^{(1)}$
}

\begin{abstract}
(1)Universidade Federal do Rio Grande do Sul (UFRGS), Departamento de Solos, Avenida Bento Gonçalves, no 7.712, CEP 91501-970 Porto Alegre, RS. E-mail: leluchavez@yahoo.com, luisaesc@yahoo.com, ibanghi@ufrgs.br, egon.meurer@ufrgs.br (2)UFRGS, Departamento de Plantas Forrageiras e Agrometeorologia. E-mail: paulocfc@ufrgs.br
\end{abstract}

\begin{abstract}
Resumo - O objetivo deste trabalho foi avaliar a diversidade metabólica e a atividade microbiana, em sistema de integração lavoura-pecuária em plantio direto, sob diferentes intensidades de pastejo e produção de soja. O experimento foi realizado em São Miguel das Missões, RS, em Latossolo Vermelho distroférrico argiloso, submetido ao pastejo a 10,20,30 e $40 \mathrm{~cm}$ de altura de azevém + aveia-preta, e sem pastejo, no inverno. A diversidade metabólica foi avaliada com microplacas Biolog EcoPlate pelo índice de diversidade de Shannon, e a atividade microbiana pelo método de hidrólise do diacetato de fluoresceína. Houve maior diversidade funcional a intensidades moderadas de pastejo $(20 \mathrm{a} 40 \mathrm{~cm})$. A maior atividade microbiológica no solo ocorreu no tratamento sem pastejo, em consequência da grande quantidade de resíduos vegetais remanescentes. A diversidade funcional da microbiota e a atividade microbiana tiveram alterações causadas pelas intensidades de pastejo, que podem ser utilizadas como indicadores de qualidade do solo, em sistema de integração lavoura-pecuária em plantio direto.
\end{abstract}

Termos de indexação: diacetato de fluoresceína, plantio direto, qualidade do solo.

\section{Metabolic diversity and microbial activity in the soil in an integrated crop-livestock system under grazing intensities}

\begin{abstract}
The objective of this work was to evaluate the metabolic diversity and the microbial activity in an integrated crop-livestock system under no-tillage, and at different grazing intensities and soybean production. The experiment was carried out in São Miguel das Missões county, in Rio Grande do Sul state, Brazil, in a clayey Rhodic Hapludox (Oxisol), subjected to grazing intensities at 10, 20,30 and $40 \mathrm{~cm}$-height of pasture with black oat + italian ryegrass, and a nongrazing treatment, in the winter. The metabolic diversity was evaluated with the Biolog EcoPlate technique, by the Shannon diversity index, and the microbial activity by the fluorescein diacetate hydrolysis method. There was higher functional diversity at the moderate grazing intensities (20 to $40 \mathrm{~cm}$ ). The highest microbial activity, in the soil, occurred in the nongrazing treatment because of the high quantity of plant residues. Microbial functional diversity and activity had alterations caused by the grazing intensities, which can be used as soil quality indicators on integrated crop-livestock systems under no-tillage.
\end{abstract}

Index terms: fluorescein diacetate, no-tillage, soil quality.

\section{Introdução}

Sistemas de integração lavoura-pecuária representam uma alternativa na intensificação do uso da terra, pois garantem a sustentabilidade dos sistemas de produção, já que diversos benefícios agronômicos e ambientais podem ser obtidos quando as atividades de uma propriedade são diversificadas com inclusão de pastagens (Russelle et al., 2007). A inserção de animais pode alterar algumas propriedades do sistema, como reciclagem de nutrientes e agregação do solo, e melhorar a sua qualidade (Ingram et al., 2008; Carvalho et al., 2010).

O funcionamento da comunidade microbiana do solo é importante para a compreensão dos processos em nível de ecossistema. Os estudos sobre bioindicadores mostram que os microrganismos do solo, por características como abundância e atividades bioquímica e metabólica, proporcionam respostas mais rápidas às mudanças no ambiente e, consequentemente, apresentam alto potencial de uso na avaliação da qualidade do solo (Six et al., 2006). 
As análises de diversidade metabólica são realizadas com base na comparação dos perfis de resposta catabólica, a partir do estudo do padrão de utilização de diferentes substratos de carbono (C) (Zak et al., 1994). Uma das formas desse tipo de estudo envolve a incubação de suspensões de solo em microplacas Biolog Ecoplate. A diversidade metabólica é definida pelo número, tipo e taxa de utilização de um conjunto de substratos pela comunidade microbiana, que é consequência da diversidade genética, dos efeitos ambientais na expressão gênica e das interações ecológicas entre as diferentes populações (Zak et al., 1994). O estudo da diversidade funcional da microbiota do solo, com uso do sistema Biolog, pode servir como um indicador de mudanças da qualidade do solo ou alterações em resposta a estresses (Papatheodorou et al., 2008).

A atividade microbiológica também tem sido utilizada como indicador de qualidade do solo. Um dos métodos de avaliação dessa atividade é a hidrólise do diacetato de fluoresceína (FDA), que mede a atividade específica de proteases, lipases, esterases e outras enzimas capazes de hidrolizar o FDA. Geralmente, mais de $90 \%$ do fluxo de energia no solo passa através de decompositores microbianos e, portanto, uma análise que mede a atividade desses microrganismos pode fornecer uma boa estimativa da atividade microbiológica total (Ghini et al., 1998).

Uma melhor compreensão dos efeitos do pastejo na microbiota do solo é necessária, para identificar intensidades de pastejo que mantenham ou melhorem a qualidade do solo, com um manejo sustentável, em sistemas de integração lavoura-pecuária.

O objetivo deste trabalho foi avaliar a diversidade metabólica e a atividade dos microrganismos como indicadores da qualidade do solo, em sistema de integração lavoura-pecuária em plantio direto, submetido a diferentes intensidades de pastejo.

\section{Material e Métodos}

O trabalho foi realizado em experimento de integração lavoura-pecuária sob sistema plantio direto, na Fazenda do Espinilho, pertencente à Cabaña Cerro Coroado, no Município de São Miguel das Missões, a $29^{\circ} 03^{\prime} \mathrm{S}, 53^{\circ} 50^{\prime} \mathrm{W}$, e à altitude média de $465 \mathrm{~m}$, na região fisiográfica do Planalto Médio, RS. O solo é classificado como Latossolo Vermelho distroférrico, na Unidade de Mapeamento Santo Ângelo (Santos et al., 2006). A área total do experimento é de aproximadamente 22 ha, dividida em parcelas experimentais, com tamanhos aproximados de 1,0 a 2,5 ha que foram ajustados em razão dos tratamentos de pressão de pastejo. Na Tabela 1, encontram-se algumas características do solo da área experimental.

O experimento iniciou-se em 2001, em área que vinha sendo cultivada em plantio direto, desde 1993, com aveia-preta (Avena strigosa Schreb.) no inverno, e soja [Glycine $\max$ (L.) Merr.] no verão. Em maio de 2001, após a colheita da soja, foi implantada uma mistura de pastagem de aveia-preta + azevém (Lolium multiflorum Lam.). Os tratamentos consistiram de manejo da pastagem com alturas de 10, 20, 30 e $40 \mathrm{~cm}$, designados por P-10, P-20, P-30, P-40, respectivamente, e sem pastejo (SP), distribuídos em delineamento de blocos ao acaso, com três repetições. Após o período de pastejo, no início de dezembro, era semeada a soja, em plantio direto, que era colhida em maio do ano seguinte. Essa sequência pastejo/soja foi repetida ano após ano. Assim, no período experimental do presente trabalho (maio a novembro de 2008), a aveia-preta foi implantada em maio, logo após a colheita da soja. A densidade de semeadura de aveia-preta foi de $100 \mathrm{~kg} \mathrm{ha}^{-1}$ de sementes, e o azevém proveio da ressemeadura natural decorrente da sua implantação em anos anteriores. A adubação de semeadura foi feita, em razão da análise do solo, para um rendimento de $4 \mathrm{Mg} \mathrm{ha}^{-1}$ de biomassa da pastagem (Manual de adubação e calagem para os estados do Rio Grande do Sul e Santa Catarina, 2004), e consistiu de $300 \mathrm{~kg} \mathrm{ha}^{-1}$ de superfosfato simples e uma aplicação de nitrogênio em cobertura, na dose $45 \mathrm{~kg} \mathrm{ha}^{-1}$ de $\mathrm{N}$ na forma de ureia, no estádio de perfilhamento da aveia.

Para o pastejo, foram utilizados 81 bovinos de corte, machos castrados, provenientes de cruzamento entre as raças Angus, Hereford e Nelore, sem grau de sangue definido, oriundos do plantel existente na propriedade. Desse total, 36 animais constituíram os animais teste, que permaneceram em pastejo durante todo o período experimental. Esses animais apresentaram peso-vivo médio inicial de $203 \pm 1,7 \mathrm{~kg}$, escore de condição corporal inicial médio de $3,47 \pm 0,02$ e idade média inicial aproximada de dez meses.

O pastejo teve início em 17/7/2008, quando a altura média do pasto atingiu $28 \mathrm{~cm}$ e cerca de $1.700 \mathrm{~kg} \mathrm{ha}^{-1}$ de massa de matéria seca. A data de entrada dos 
animais ocorreu em razão do protocolo experimental, estabelecido desde 2001, que visa o início do pastejo na segunda quinzena do mês de julho, de modo a facilitar o manejo das operações na propriedade. A permanência dos animais na área estendeu-se por 122 dias, até 15/11/2008, quando foram retirados e encaminhados ao abate. O controle da intensidade de pastejo contínuo foi obtido com a variação do número de animais controladores por área, tendo-se retirado os animais das parcelas quando a altura real era menor que a pretendida e vice-versa.

As coletas de solo foram realizadas em outubro de 2008, na camada de $0-10 \mathrm{~cm}$, em 20 pontos ao acaso por parcela, que formaram uma amostra composta e representativa de cada tratamento, com três repetições. As amostras foram acondicionadas em caixas de isopor e refrigeradas com gelo, para o transporte até o Laboratório de Microbiologia do Solo, do Departamento de Solos da Universidade Federal do Rio Grande do Sul. Posteriormente, no laboratório, as raízes foram retiradas, e o solo foi passado em peneira de $2 \mathrm{~mm}$ de abertura.

Os padrões de utilização de substratos pela população microbiana do solo foram determinados com microplacas Biolog Ecoplate (Biolog Inc., Hayward, CA, EUA), conforme Bloem et al. (2006). Nesse procedimento, $10 \mathrm{~g}$ de solo foram adicionadas a tubos de Erlenmayer com $190 \mathrm{~mL}$ de solução salina $(\mathrm{NaCl}$ 0,85\%) esterilizada. Essas suspensões foram dispersas por $25 \mathrm{~min}$ em agitador orbital a 4,48 $g$. Após 4 min de decantação, o sobrenadante foi transferido para tubo esterilizado, que foi centrifugado a $4.445,28 \mathrm{~g}$, por $20 \mathrm{~min}$, a $4^{\circ} \mathrm{C}$. O sobrenadante foi descartado, e o pélete ressuspendido em $20 \mathrm{~mL}$ da solução salina. Após 2 horas de decantação, alíquotas de $120 \mu \mathrm{L}$ do sobrenadante foram adicionadas às cavidades das microplacas Biolog Ecoplate. Cada microplaca é composta por três grupos de 31 diferentes substratos de $\mathrm{C}$ (ácidos carboxílicos, carboidratos, polímeros, aminoácidos e amidos), além da testemunha (cavidade sem substrato). Para cada amostra coletada no campo, utilizou-se uma microplaca que foi incubada a $28^{\circ} \mathrm{C}$ por 48 horas. $\mathrm{O}$ crescimento microbiano, avaliado pelo aumento da absorbância, foi determinado por espectrofotometria a $590 \mathrm{~nm}$, com um leitor de microplacas Titertek Multiskan PLUS MKII (Labsystems, Helsinque, Finlândia). A capacidade de utilizar uma fonte de $\mathrm{C}$ foi determinada conforme Ibekwe \& Kennedy (1998), pela equação: $\mathrm{W}_{\mathrm{E}}=100\left(\mathrm{~W}_{\mathrm{A}}-\mathrm{W}_{0}\right) / \mathrm{W}_{0}$, em que: $\mathrm{W}_{\mathrm{E}}$ é o índice de desenvolvimento da cor, $\mathrm{W}_{\mathrm{A}}$ é a absorbância de cada cavidade, e $\mathrm{W}_{0}$ é a absorbância do branco. A condição para que a reação seja positiva é a de que $\mathrm{W}_{\mathrm{E}}$ seja superior a 100. O índice de diversidade de Shannon $(\mathrm{H})$, que compreende tanto a riqueza de substratos como a intensidade com que eles foram usados pela microbiota, foi calculado de acordo com Zak et al. (1994), pela equação: $H=-\Sigma p_{i}\left(\ln p_{i}\right)$, em que $H$ é o índice de diversidade de Shannon, e $\mathrm{p}_{\mathrm{i}}$ é a razão entre a atividade de utilização de determinado substrato e a atividade de utilização de todos os substratos.

A atividade enzimática ou atividade microbiológica do solo foi avaliada pela hidrólise do diacetato de fluoresceína. Esse substrato é hidrolisado por diversas enzimas do solo, como proteases, lipases e esterases, que o qualificam como uma medida da atividade microbiana total do solo. A determinação foi realizada conforme o procedimento descrito em Bandick \& Dick (1999). Foi misturado $1 \mathrm{~g}$ de solo com $20 \mathrm{~mL}$ de solução tampão de fosfato de sódio a $60 \mathrm{~mol} \mathrm{~L}^{-1} \mathrm{e}$ $100 \mu \mathrm{mol} \mathrm{L}{ }^{-1}$ de solução estoque de FDA. As amostras foram agitadas por 2 horas em agitador a $100 \mathrm{rpm}$, a $25^{\circ}$ C. Foi feito um controle de cada amostra, em que só foi adicionado o substrato depois de 2 horas de agitação. Em seguida, foram adicionados $20 \mathrm{~mL}$ de acetona para finalizar a reação enzimática. Nos controles, foram adicionados $100 \mu \mathrm{mol} \mathrm{L}^{-1}$ da solução estoque de FDA e, imediatamente, $20 \mathrm{~mL}$ de acetona. As soluções foram centrifugadas por $5 \mathrm{~min}$ a $4.032 \mathrm{~g}$, filtradas em papel de filtro Whatman no 4 e, em seguida, submetidas à leitura de absorbância a $490 \mathrm{~nm}$ em espectrofotômetro.

Tabela 1. Características do Latossolo Vermelho distroférrico da área experimental, no estabelecimento da pastagem em sistema de integração lavoura-pecuária em plantio direto ${ }^{(1)}$.

\begin{tabular}{|c|c|c|c|c|c|c|c|c|}
\hline $\begin{array}{l}\text { Profundidade } \\
(\mathrm{cm})\end{array}$ & $\begin{array}{c}\mathrm{pH} \\
\text { (em água) }\end{array}$ & $\begin{array}{c}\text { Carbono } \\
\left(\mathrm{g} \mathrm{kg}^{-1}\right)\end{array}$ & $\begin{array}{c}\mathrm{P} \\
---( \\
\end{array}$ & $\begin{array}{c}\mathrm{K} \\
3)---- \\
\end{array}$ & $\mathrm{Ca}$ & $\begin{array}{l}\mathrm{Mg} \\
\mathrm{l}_{\mathrm{c}} \mathrm{dr} \\
\end{array}$ & Al & $\begin{array}{c}\text { Argila } \\
\left(\mathrm{g} \mathrm{kg}^{-1}\right)\end{array}$ \\
\hline $0-10$ & 4,7 & 40 & 15,0 & 102 & 5,3 & 2,8 & 1,3 & 540 \\
\hline $10-20$ & 3,9 & 29 & 6,2 & 87 & 3,4 & 2,1 & 5,0 & 560 \\
\hline
\end{tabular}

${ }^{(1)} \mathrm{P}$ e K, extrator Mehlich 1; Ca, $\mathrm{Mg}$ e Al, extrator $\mathrm{KCl} 1,0 \mathrm{~mol} \mathrm{~L}^{-1}$. 
Com os dados obtidos, foi elaborada uma curva-padrão e calculada a quantidade de fluoresceína hidrolisada.

Os efeitos da intensidade de pastejo sobre a diversidade metabólica e a atividade microbiana foram verificados pela análise descritiva dos dados, com uso do erro-padrão da média. A relação entre variáveis microbiológicas e altura da pastagem foi avaliada pela significância do coeficiente de determinação $\left(\mathrm{R}^{2}\right)$ dos modelos de regressão polinomial. Foi realizada, também, a análise de correlação de Pearson entre a diversidade metabólica e a atividade microbiana, com os seguintes indicadores de qualidade do solo: diâmetro médio ponderado dos agregados (Kemper \& Chepil, 1965), índice de manejo de carbono (Blair et al., 1995), biomassa microbiana (Mendonça \& Matos, 2005), respiração basal diária (Alef \& Nannipieri, 1995) e quociente metabólico (Anderson \& Domsch, 1993), conforme determinado por Souza (2008).

\section{Resultados e Discussão}

Os valores de diversidade metabólica, medidos por meio do índice de Shannon, variaram de 6,93 $\pm 0,29$ a 7,42 $\pm 0,07$ nas áreas sem pastejo e P-30, respectivamente, e são superiores àqueles reportados $(2,0$ a 4,5) para sistemas de manejo com plantas de cobertura, em sucessão a culturas comerciais (grãos), em solos de regiões temperadas (Papatheodorou et al., 2008; Jacinthe et al., 2010). Provavelmente, a maior interação solo-planta, na mistura da pastagem de aveia-preta + azevém, associada às condições climáticas em que foi realizado o presente trabalho, favoreceu a diversidade da microbiota do solo. Assim, a maioria dos exsudatos produzidos na rizosfera deve ter permitido a competitividade de um número maior de espécies de microrganismos, o que garante maior diversidade conforme Papatheodorou et al. (2008). A relação polinomial quadrática, entre a altura média de pastejo e o índice de Shannon, indicou maior diversidade (Figura 1 A) e intensidade (Tabela 2) metabólica da comunidade microbiana, nas intensidades moderada à leve de pastejo (P-20 a P-40). Esses resultados podem estar associados ao fato de que o corte da parte área da pastagem promove aumento na exsudação de compostos orgânicos pelas raízes, além de aumento da rizosfera (Tisdall \& Oades, 1982). Assim, quanto maior a presença de raízes, maior será a exsudação de compostos orgânicos que servirão como fonte de $\mathrm{C}$ e de energia à população microbiana, o que favorecerá seu aumento e diversidade.

Resultados semelhantes têm sido observados por outros pesquisadores, em que intensidades moderadas de pastejo têm sido capazes de manter ou melhorar
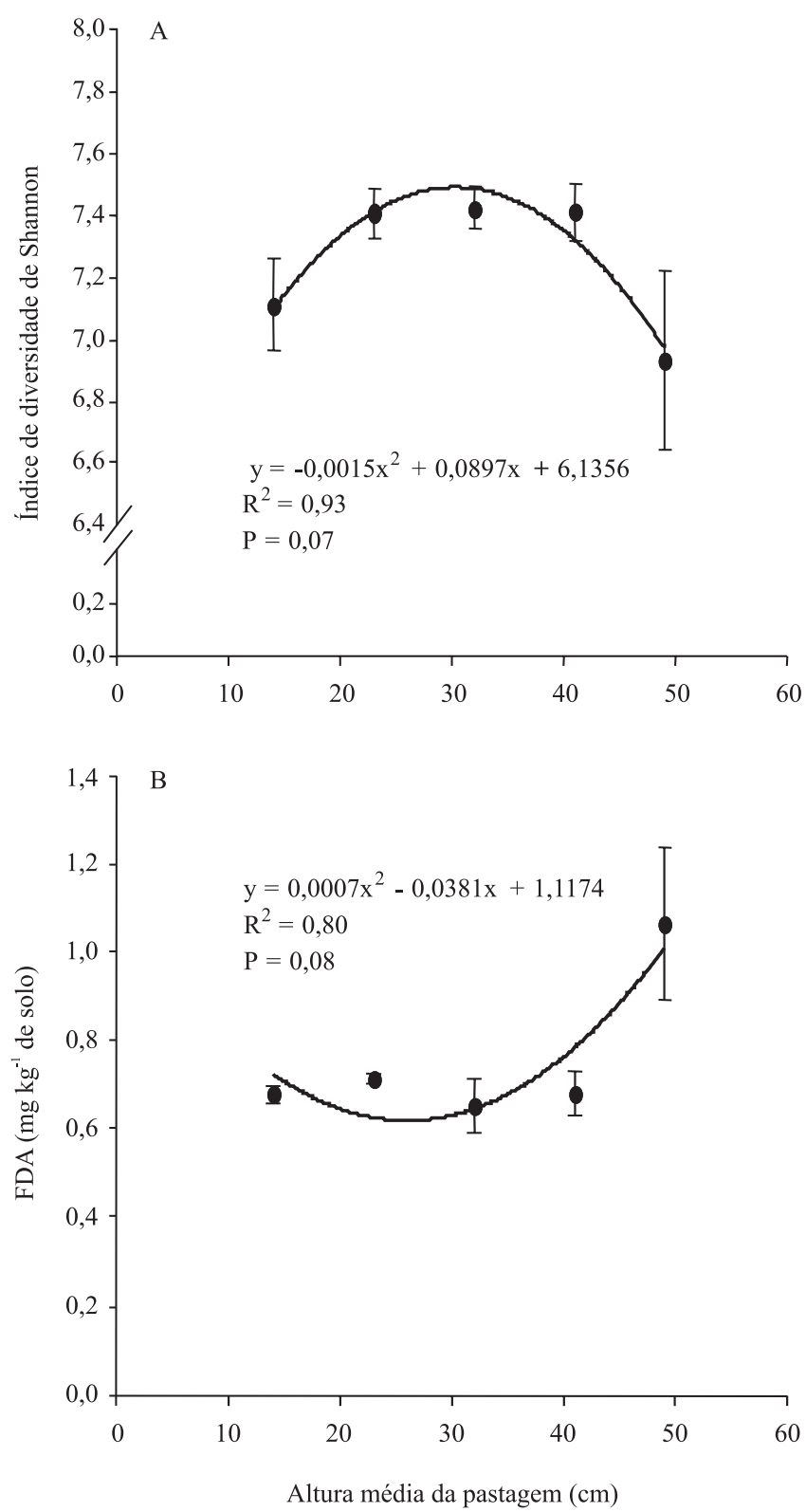

Figura 1. Índice de diversidade de Shannon, com base na capacidade de utilização de substratos de carbono pelos microrganismos no solo (A), e quantidade de diacetato de fluoresceína (FDA) hidrolisada pelos microrganismos (B), em solo submetido a intensidades de pastejo, em sistema de integração lavoura-pecuária em plantio direto. As barras verticais representam o erro-padrão da média. 
as propriedades químicas e físicas do solo (Carvalho et al., 2010), ao mesmo tempo em que maximizam a disponibilidade de recursos para a microbiota do solo e para todos os processos que esta controla (Ingram et al., 2008). O pastejo em intensidades moderadas pode influenciar positivamente a diversidade e intensidade funcionais da microbiota no solo. Segundo Clegg (2006), o pastejo exerce um papel importante na ecologia microbiana do solo, por meio de uma série de fatores específicos associados à presença dos animais, como a deposição de urina e esterco, e a compactação do solo.

A similaridade na diversidade funcional da microbiota, nas intensidades moderadas de pastejo (Figura $1 \mathrm{~A}$ ), mesmo com algumas diferenças nos quatro substratos mais utilizados (Tabela 2), indica a homogeneidade na composição bioquímica dos resíduos vegetais e de origem animal, que são adicionados nessas áreas, conforme sugerido em Bending et al. (2002). A diversidade de bactérias do solo aumenta com o aumento da diversidade vegetal, possivelmente em consequência de diferenças na composição dos exsudatos entre os tipos de plantas e, também, para as mesmas espécies vegetais em diferentes fases de desenvolvimento (Benizri \& Amiaud, 2005). Os diversos tipos e quantidades desses compostos têm sido postulados como os principais fatores que influenciam a densidade e a diversidade de microrganismos na rizosfera (Bolton Junior et al., 1992).

A maior intensidade de pastejo (P-10) teve índice de diversidade menor do que os outros tratamentos com pastejo. O pastejo intenso pode causar redução na abundância dos macroporos do solo, com consequente deficiência de oxigênio, o que resulta em menor diversidade bacteriana (Clegg, 2006; Papatheodorou et al., 2008; Wakelin et al., 2009). Em experimento realizado nas mesmas áreas do presente trabalho, Conte et al. (2007) e Flores et al. (2007) observaram aumento na densidade do solo, na resistência à penetração de raízes, e redução da porosidade total e na macroporosidade do solo, especialmente no tratamento com maior pressão de pastejo.

Com alta intensidade de pastejo, menor quantidade de resíduos permanece na superfície do solo $\left( \pm 2,85 \mathrm{Mg} \mathrm{ha}^{-1}\right.$ por ano), o que resulta em menores adições de $\mathrm{C}$ e de outros nutrientes como nitrogênio, fósforo e potássio, causa declínio na qualidade do solo (Carvalho et al., 2010) e afeta negativamente a microbiota do solo e os processos por ela controlados (Ingram et al., 2008). No presente trabalho, esses fatores, provavelmente, causaram impacto negativo na diversidade metabólica da população microbiana no P-10.

O menor valor do índice de Shannon, observado no SP (Figura $1 \mathrm{~A}$ ), mesmo com alta deposição de resíduos $\left( \pm 5,26 \mathrm{Mg} \mathrm{ha}^{-1}\right.$ por ano), indica diminuição da atividade rizosférica nessa área pela ausência de pastejo, o que reduz a exsudação. O comportamento funcional da microbiota do solo é influenciado pela atividade rizosférica, que determina a quantidade e a composição dos exsudatos disponibilizados para os microrganismos (Garland, 1996). O pastejo aumenta a disponibilidade de $\mathrm{C}$ para a comunidade microbiana do solo, seja diretamente, por meio da adição de resíduos vegetais e de origem animal, ou indiretamente, por meio da alteração na alocação ou nos fluxos de $\mathrm{C}$ na rizosfera (Wakelin et al., 2009). Entretanto, se esta característica não está presente nessa área, a diversidade funcional é afetada negativamente, talvez por falta de substratos para o metabolismo microbiano.

A estimulação de microrganismos capazes de utilizar diferentes carboidratos como N-acetil-D-glucosamina, D-celobiose, D-manitol, D-xilose, $\alpha$-D-lactose e o aminoácido L-asparagina, nos tratamentos avaliados (Tabela 2), indica que as espécies vegetais (aveia +

Tabela 2. Substratos mais utilizados e capacidade de utilização de fontes de C pela microbiota, determinada pelo índice de desenvolvimento da cor (IDC), em solo submetido a intensidades de pastejo, em sistema de integração lavoura-pecuária em plantio direto(1).

\begin{tabular}{|c|c|c|c|c|c|c|c|c|}
\hline Intensidade de pastejo & Substrato & IDC & Substrato & IDC & Substrato & IDC & Substrato & IDC \\
\hline $\mathrm{P}-10$ & N-acetil-D-glicosamina & 594 & L-asparagina & 531 & D-manitol & 515 & ácido D-málico & 474 \\
\hline P-20 & $\mathrm{N}$-acetil-D-glicosamina & 736 & D-manitol & 723 & D-celobiose & 666 & D-xilose & 603 \\
\hline P-30 & D-celobiose & 817 & D-manitol & 768 & $\alpha$-D-lactose & 742 & $\mathrm{~N}$-acetil-D-glicosamina & 728 \\
\hline P-40 & D-manitol & 600 & D-celobiose & 573 & $\alpha$-D-lactose & 556 & $\mathrm{~N}$-acetil-D-glicosamina & 555 \\
\hline SP & $\mathrm{N}$-acetil-D-glicosamina & 568 & D-xilose & 562 & L-asparagina & 520 & D-celobiose & 516 \\
\hline
\end{tabular}

(1)IDC superior a 100 indica reação positiva e, portanto, o substrato foi metabolizado; P-10, P-20, P-30, P-40, manejo do pasto, com alturas de 10, 20 , 30 e $40 \mathrm{~cm}$, respectivamente, obtidas por alterações na taxa de lotação dos animais; pois quanto menor a altura do pasto, maior a taxa de lotação; SP, sem pastejo. 
azevém) estabelecidas na área experimental podem liberar compostos desse tipo em sua rizosfera (Gömöryová et al., 2009). A adição de maior diversidade de fontes de $\mathrm{C}$ no solo resulta em maior utilização desses compostos pelas comunidades microbianas do solo sob pastagens (Grayston et al., 2001). No entanto, os exsudatos liberados pelas plantas, especialmente os aminoácidos e os carboidratos, devem ser analisados para confirmar essa hipótese.

Os valores de hidrólise de FDA variaram de

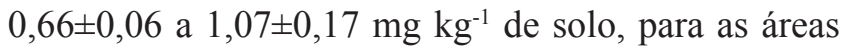
P-30 e sem pastejo, respectivamente (Figura $1 \mathrm{~B}$ ). Entretanto, a atividade enzimática foi considerada uniforme nas áreas pastejadas, tendo variado somente de $0,66 \pm 0,06$ a $0,72 \pm 0,01$. Mesmo assim, a resposta da hidrólise de FDA à altura de pastejo foi descrita por uma relação polinomial quadrática que, entretanto, teve altos valores de atividade enzimática no tratamento SP. O tratamento SP disponibiliza maior quantidade de resíduos vegetais sobre o solo $\left( \pm 5,26 \mathrm{Mg} \mathrm{ha}^{-1}\right.$ por ano), o que representa grande quantidade de material prontamente decomponível pelos microrganismos. A atividade microbiana na camada amostrada de solo (0-10 cm), com uso da hidrólise do FDA, aumenta em função do maior acúmulo de matéria orgânica na superfície do solo (Bandick \& Dick, 1999). Segundo Bending et al. (2002), a atividade da maioria das enzimas aumenta à medida que aumenta a matéria orgânica do solo. A maior cobertura do solo, resultante da quantidade de resíduos vegetais na superfície da área SP, favorece a manutenção de maior conteúdo de água no solo e maior estoque de $\mathrm{C}$ e $\mathrm{N}$, que estimulam a atividade da microbiota (Carvalho et al., 2010). Com a diminuição da intensidade de pastejo, aumenta a quantidade de resíduos presentes sobre o solo, pois menor quantidade da biomassa de forragem é consumida e, consequentemente, permanece na superfície (Conte et al., 2007).

As baixas atividades enzimáticas nas áreas pastejadas, em comparação às áreas sem pastejo, no sistema de integração lavoura-pecuária, podem ocorrer em razão da redução na biomassa vegetal e, consequentemente, da redução dos nutrientes e da umidade do solo, com efeitos nocivos para as comunidades microbianas (Acosta-Martínez et al., 2010).

A diversidade metabólica da microbiota, nos tratamentos avaliados, somente teve correlação positiva com o diâmetro médio ponderado (Tabela 3), o que mostra que a maior utilização de substratos de $\mathrm{C}$, por parte dos microrganismos, implica em maior agregação do solo. O aumento da diversidade metabólica ocasiona maior produção de agentes cimentantes, que contribuem para maior estabilidade dos agregados. Além disso, os macroagregados que são ricos em $\mathrm{C}$ e $\mathrm{N}$ lábil servem de substrato para os microrganismos (Six et al., 2006).

Apesar de o índice de Shannon e a atividade microbiana não terem tido correlação significativa $(p<0,05)$ com os demais indicadores de qualidade do solo (Tabela 3), o fato de as áreas com intensidades moderadas de pastejo apresentarem maior diversidade metabólica da comunidade microbiana e menor atividade enzimática pode indicar que elas se encontram em estado de maior instabilidade termodinâmica, que imprime ao sistema maior capacidade de auto-organização (Vezzani \& Mielniczuk, 2009). Essa hipótese é reforçada pela ocorrência - no pastejo moderado - em adição à maior agregação do solo, de maior estoque e labilidade de $\mathrm{C}$ e de quociente metabólico, conforme observado por Souza et al. (2009), no ciclo de pastejo do mesmo experimento em 2007. No enfoque sistêmico, a integração lavoura-pecuária sob plantio direto favorece o surgimento de propriedades emergentes (Vezzani \& Mielniczuk, 2009), pela inclusão dos animais a intensidades moderadas de pastejo, que reciclam o material vegetal e modificam a dinâmica da ciclagem de nutrientes, em comparação a sistemas em que as coberturas de inverno são produzidas somente para proporcionar cobertura ao solo (Carvalho et al., 2010).

A variabilidade espacial e temporal dos sistemas de pastejo indicam a necessidade de realização de estudos futuros, com coletas mais intensivas, para caracterizar melhor o comportamento da comunidade microbiana. Modificações temporais na quantidade e na qualidade

Tabela 3. Correlação entre diversidade metabólica funcional e atividade microbiana, com indicadores de qualidade, em solo submetido a intensidades de pastejo, em sistema de integração lavoura-pecuária em plantio direto ${ }^{(1)}$.

\begin{tabular}{|c|c|c|c|c|c|}
\hline Indicador & DMP & IMC & C-BMS & RBD & $\mathrm{qCO}_{2}$ \\
\hline Îndice de Shannon & $0,97 *$ & $0,37^{\mathrm{ns}}$ & $0,21^{\mathrm{ns}}$ & $0,52^{\text {ns }}$ & $0,38^{\mathrm{ns}}$ \\
\hline Atividade da FDA ${ }^{(2)}$ & $-0,68^{\mathrm{ns}}$ & $0,30^{\mathrm{ns}}$ & $-0,73^{\text {ns }}$ & $-0,93^{\text {ns }}$ & $0,10^{\mathrm{ns}}$ \\
\hline
\end{tabular}

(1)DMP, diâmetro médio ponderado; IMC, índice de manejo de carbono; C-BMS, carbono na biomassa bacteriana; RBD, respiração basal diária; $\mathrm{qCO}_{2}$, quociente metabólico (Souza et al., 2009). ${ }^{(2)} \mathrm{FDA}$, acetato de fluoresceína. ${ }^{\text {nn}}$ Não significativo. *Significativo a $5 \%$ de probabilidade. 
dos compostos orgânicos, depositados na rizosfera, podem atuar como uma pressão de seleção para a biota do solo (Wakelin et al., 2009). A diversidade funcional das comunidades microbianas do solo também pode variar com a época de amostragem e, aparentemente, essas comunidades nas pastagens estão fortemente influenciadas pela composição e fenologia da comunidade vegetal (Benizri \& Amiaud, 2005; Papatheodorou et al., 2008). Mudanças nos perfis catabólicos, em razão de um efeito sinérgico das interações solo-planta, e a variabilidade climática sazonal podem predominar sobre as mudanças induzidas por diferentes sistemas de manejo agrícola (Papatheodorou et al., 2008).

\section{Conclusões}

1. A intensidades moderadas $(20 \mathrm{a} 40 \mathrm{~cm})$ de pastejo de azevém com aveia-preta, em sistema de integração lavoura-pecuária em plantio direto, a diversidade funcional da microbiota é maior em comparação a áreas com alta intensidade de pastejo e áreas não pastejadas.

2. A atividade microbiana, medida pela hidrólise de diacetato de fluoresceína, é semelhante nas diversas áreas pastejadas, porém menor do que na área não pastejada.

3. A diversidade funcional da microbiota e a atividade microbiana sofrem alterações causadas por intensidades de pastejo e podem ser utilizadas como indicadoras de qualidade do solo.

\section{Referências}

ACOSTA-MARTÍNEZ, V.; BELL, C.W.; MORRIS, B.E.L.; ZAK, J.; ALLEN, V.G. Long-term soil microbial community and enzyme activity responses to an integrated cropping-livestock system in a semi-arid region. Agriculture, Ecosystems and Environment, v.137, p.231-240, 2010.

ALEF, K.; NANNIPIERI, P. Methods in applied soil microbiology and biochemistry. London: Academic, 1995. 576p.

ANDERSON, T.H.; DOMSCH, K.H. The metabolic quotient for $\mathrm{CO}_{2}\left(q \mathrm{CO}_{2}\right)$ as a specific activity parameter to assess the effects of environmental conditions, such as $\mathrm{pH}$, on the microbial biomass of forest soils. Soil Biology and Biochemistry, v.25, p.393-395, 1993.

BANDICK, A.K.; DICK, R.P. Field management effects on soil enzyme activities. Soil Biology and Biochemistry, v.31, p.1471-1479, 1999.

BENDING, G.D.; TURNER, M.K.; JONES, J.E. Interactions between crop residue and soil organic matter quality and functional diversity of soil microbial communities. Soil Biology and Biochemistry, v.34, p.1073-1082, 2002.

BENIZRI, E.; AMIAUD, B. Relationship between plants and soil microbial communities in fertilized grasslands. Soil Biology and Biochemistry, v.37, p.2055-2064, 2005.

BLAIR, G.J.; LEFROY, R.D.B.; LISLE, L. Soil carbon fractions based on their degree of oxidation, and the development of a carbon management index, for agricultural systems. Australian Journal of Agricultural Research, v.46, p.1459-1466, 1995.

BLOEM, J.; SCHOUTEN, A.J.; SORENSEN, S.J.; RUTGERS, M.; WERF, A.; BREURE, A.M. Monitoring and evaluating soil quality. In: BLOEM, J.; HOPKINS, D.W.; BENEDETTI, A. (Ed.). Microbiological methods for assessing soil quality. Wallingford: CABI, 2006. p.23-49.

BOLTON JUNIOR, H.; FREDRICKSON, J.K.; ELLIOT, L.F. Microbial ecology of the rhizosphere. In: METTING JUNIOR, F.B. (Ed.). Soil microbial ecology: applications in agricultural and environmental management. New York: Marcel Dekker, 1992. p.27-63.

CARVALHO, P.C. de F.; ANGHINONI, I.; MORAES, A. de; SOUZA, E.D. de; SULC, R.M; LANG, C.R.; FLORES, J.P.C.; LOPES, M.L.T.; SILVA, J.L.S. da; CONTE, O.; WESP, C. de L.; LEVIEN, R.; FONTANELI, R.S.; BAYER, C. Managing grazing animals to achieve nutrient cycling and soil improvement in no-till integrated systems. Nutrient Cycling in Agroecosystems, v.88, p.259-273, 2010 .

CLEGG, C.D. Impact of cattle grazing and inorganic fertiliser additions to managed grasslands on the microbial community composition of soils. Applied Soil Ecology, v.31, p.73-82, 2006.

CONTE, O.; LEVIEN, R.; TREIN, C.R.; CEPIK, C.T.C.; DEBIASI, H. Demanda de tração em haste sulcadora na integração lavoura-pecuária com diferentes pressões de pastejo e sua relação com o estado de compactação do solo. Engenharia Agrícola, v.27, p.220-228, 2007.

FLORES, J.P.C.; ANGHINONI, I.; CASSOL, L.C.; CARVALHO, P.C. de F.; LEITE, J.G. Dal B.; FRAGA, T.I. Atributos físicos do solo e rendimento de soja em sistema plantio direto em integração lavoura-pecuária com diferentes pressões de pastejo. Revista Brasileira de Ciência do Solo, v.31, p.771-780, 2007.

GARLAND, J.L. Patterns of potential C source utilization by rhizosphere communities. Soil Biology and Biochemistry, v.28, p.223-230, 1996.

GHINI, R.; MENDES, M.D.L.; BETTIOL, W. Método de hidrólise de diacetato de fluoresceína (FDA) como indicador de atividade microbiana no solo e supressividade a Rhizoctonia solani. Summa Phytopathologica, v.24, p.239-242, 1998.

GÖMÖRYOVÁ, E.; HRIVNÁK, R.; JANIŠOVÁ, M.; UJHÁZY,K.; GÖMÖRY, D. Changes of the functional diversity of soil microbial community during the colonization of abandoned grassland by a forest. Applied Soil Ecology, v.43, p.191-199, 2009.

GRAYSTON, S.J.; GRIFFITH, G.S.; MAWDSLEY, J.L.; CAMPBELL, C.D.; BARDGETT, R.D. Accounting for variability in soil microbial communities of temperate upland grassland 
ecosystems. Soil Biology and Biochemistry, v.33, p.533-551, 2001.

IBEKWE, A.M.; KENNEDY, A.C. Phospholipid fatty acid profiles and carbon utilization patterns for analysis of microbial community structure under field and greenhouse conditions. FEMS Microbiology Ecology, v.26, p.151-163, 1998.

INGRAM, L.J.; STAHL, P.D.; SCHUMAN, G.E.; BUYER, J.S.; VANCE, G.F.; GANJEGUNTE, G.K.; WELKER, J.M.; DERNER, J.D. Grazing impacts on soil carbon and microbial communities in a mixed-grass ecosystem. Soil Science Society of America Journal, v.72, p.939-948, 2008.

JACINTHE, P.; BILLS, J.S; TEDESCO, L.P. Size, activity and catabolic diversity of the soil microbial biomass in a wetland complex invaded by reed canary grass. Plant and Soil, v.329, p.227-238, 2010.

KEMPER, W.D.; CHEPIL, W.S. Size distribution of aggregates. In: BLACK, C.A.; EVANS, D.D.; WHITE, J.L.; ENSMINGER, L.E.; CLARK, F.E.; DINAUER, R.C. (Ed). Methods of soil analysis. Madison: American Society of Agronomy, 1965. p.499-510.

MANUAL de adubação e calagem para os Estados do Rio Grande do Sul e de Santa Catarina. 10.ed. Porto Alegre: Sociedade Brasileira de Ciência do Solo/Comissão de Química e Fertilidade do Solo, 2004. 400p.

MENDONÇA, E. de S.; MATOS, E. da S. Matéria orgânica do solo: métodos de análises. Viçosa: UFV, 2005. 107p.

PAPATHEODOROU, E.M.; EFTHIMIADOU, E.; STAMOU, G.P. Functional diversity of soil bacteria as affected by management practices and phenological stage of Phaseolus vulgaris. European Journal of Soil Biology, v.44, p.429-436, 2008.

RUSSELlE, M.P.; ENTZ, M.H.; FRANZLUEBBERS, A.J. Reconsidering integrated crop-livestock systems in North America. Agronomy Journal, v.99, p.325-334, 2007.
SANTOS, H.G. dos; JACOMINE, P.K.T.; ANJOS, L.H.C. dos; OLIVEIRA, V.A. de; OLIVEIRA, J.B. de; COELHO, M.R.; LUMBRERAS, J.F.; CUNHA, T.J.F. (Ed.). Sistema brasileiro de classificação de solos. 2.ed. Rio de Janeiro: Embrapa Solos, 2006. $306 \mathrm{p}$.

SIX, J.; FREY, S.D.; THIES, R.K.; BATTEN, K.M. Bacterial and fungal contributions to carbon sequestration in agroecosystems. Soil Science Society of America Journal, v.70, p.555-569, 2006.

SOUZA, E.D. de. Evolução da matéria orgânica, do fósforo e da agregação em sistema de integração agricultura-pecuária em plantio direto, submetido a intensidades de pastejo. 2008. 163p. Tese (Doutorado) - Universidade Federal do Rio Grande do Sul, Porto Alegre.

SOUZA, E.D. de; COSTA, S.E.V.G. de A.; ANGHINONI, I.; CARVALHO, P.C. de F.; ANDRIGUETI, M.; CAO, E. Estoques de carbono orgânico e de nitrogênio no solo em sistema de integração lavoura-pecuária em plantio direto, submetido a intensidades de pastejo. Revista Brasileira de Ciência do Solo, v.33, p. 1829-1836, 2009.

TISDALL, J.M.; OADES, J.M. Organic matter and water-stable aggregates in soil. Journal of Soil Science, v.33, p.141-163, 1982.

VEZZANI, F.M.; MIELNICZUK, J. Uma visão sobre qualidade do solo. Revista Brasileira de Ciência do Solo, v.33, p.743-755, 2009.

WAKELIN, S.A.; GREGG, A.L.; SIMPSON, R.J.; LI, G.D.; RILEY, I.T.; MCKAY, A.C. Pasture management clearly affects soil microbial community structure and N-cycling bacteria. Pedobiologia, v.52, p.237-251, 2009.

ZAK, J.C.; WILLIG, M.R.; MOORHEAD, D.L.; WILDMAN, H.G. Functional diversity of microbial communities: a quantitative approach. Soil Biology and Biochemistry, v.26, p.1101-1108, 1994.

Recebido em 31 de julho de 2010 e aprovado em 29 de setembro de 2011 